\title{
Isolated congenital foramen transversarium abnormality causing occipital headache
}

\author{
S Senthilnathan ${ }^{1}, M_{\text {Rajitha }}^{2}$ \\ Ceylon Medical Journal 2011; 56: 35-37
}

\section{Introduction}

Occipital neuralgia is usually unilateral and has a characteristic shock like pain lasting for a short duration indicative of neural origin [1]. The pain is confined to the dermatome of the nerve root at the lower occipital region of scalp and upper neck. The C3 nerve root compression can occur at the spinal canal lateral recess, neural foramina and lateral to the foramina. Compression of the nerve root by an abnormal course of vertebral artery has been reported in the literature. Bony abnormalities at the craniovertebral junction can cause occipital headache due to abnormal course of vertebral artery and joint instability [2,3]. Foramen transversarium defect of upper cervical vertebrae though not included in the cervicovertebral junction anomaly, when anomalous can cause occipital headache as in this case.

\section{Case report}

A 34-year old man presented with sudden onset of lancinating pain in the left occipital region and upper neck on and off. The pain occurred in left lateral decubitus position and was a momentary pain below the external occipital protuberance. His initial computed tomography (CT) of the brain was normal. His vision and hearing were normal. He was initially diagnosed as having migraine and was on medication for one year. The pain recurred on and off with or without medication. MRI of the cervical spine revealed a medially placed dominant left vertebral artery causing compression of the C3 nerve root (Figure 1). The left pedicle of C2 vertebra was small. No other craniovertebral anomaly was detected. Flexion and extension MRI excluded atlantoaxial dislocation. MRI brain and MR angiogram were normal. A CT revealed an abnormally wide foramen transversarium of $\mathrm{C} 2$ and $\mathrm{C} 1$ vertebrae (Figures 2 and 3). The C1 and C2 foramen transversarium had hypoplastic anterior costal bars. Contrast examination revealed medially displaced left vertebral artery within the $\mathrm{C} 2$ vertebral foramen. A large lateral loop of vertebral artery was also noted between the C2 and C1 vertebrae. Surgical decompression of the nerve root with repositioning of vertebral artery would have been ideal but the patient opted for non surgical management. Hence, postural advice was given. On follow up, the patient had momentary pain at the left occipital region while lying in the left lateral position which disappeared on changing the position. As surgery was not performed, a causal relationship of the displaced vertebral artery and the headache could not be established with certainty. However, as the symptoms were relieved with postural change, it was reasonable to assume that the displaced artery causing irritation of the cervical nerve root was the reason for the headache.

\footnotetext{
${ }^{1}$ Department of Radiology and Imaging, Vinayaka Mission Hospital, and ${ }^{2}$ Department of Anatomy, Vinayaka Mission Kirupananda Variyar Medical College, Salem, Tamil Nadu, India.
}

Correspondence: SS, e-mail <ssnathan05@gmail.com>. Received 14 May and revised version accepted 9 December 2010. Competing interests: none declared. 


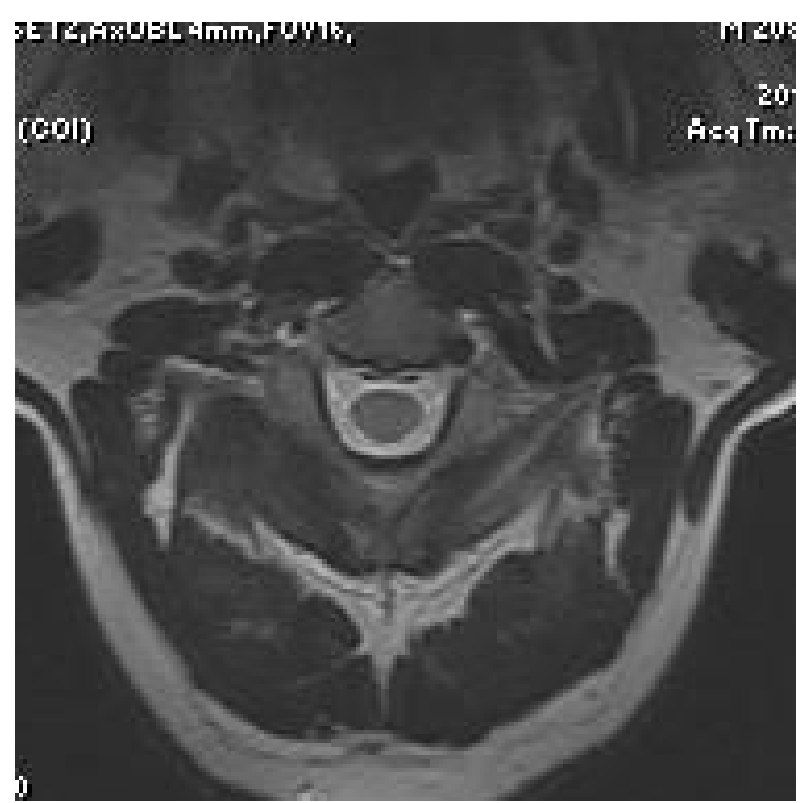

Figure 1. MRI showing medially displaced left vertebral artery compressing.

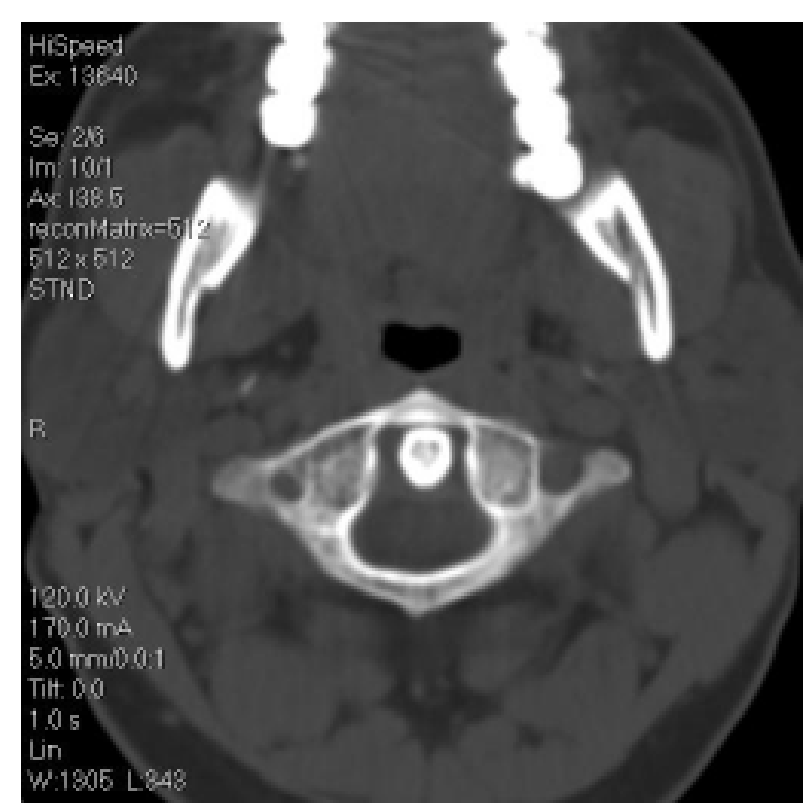

Figure 2. CT showing hypoplastic and widened left C1 foramen transversarium.

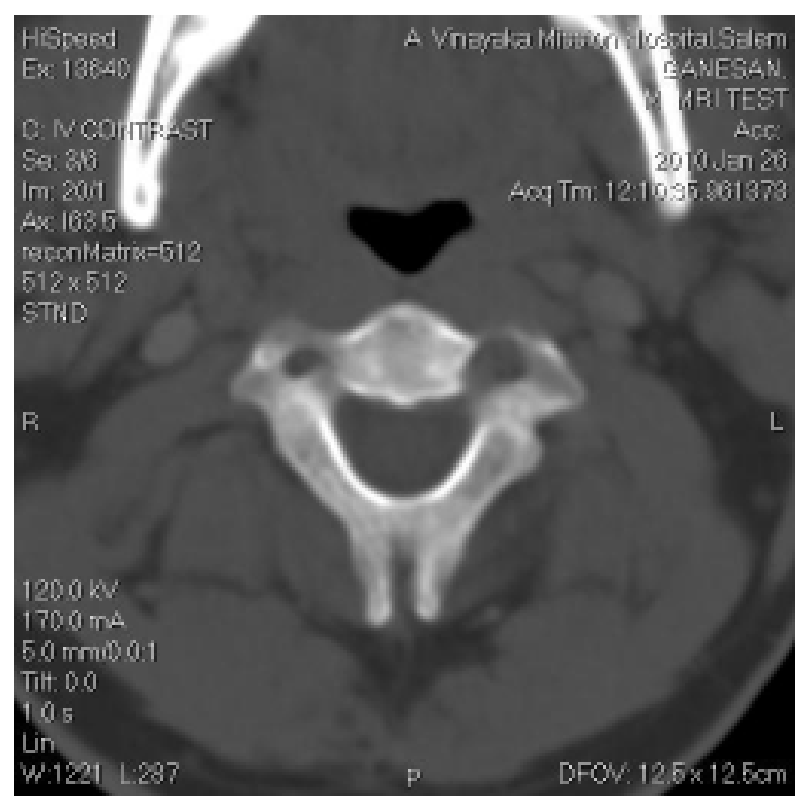

Figure 3. CT showing hypoplastic and widened left C2 foramen transversarium with thin anterior coastal bar.

\section{Discussion}

The transverse process of the cervical vertebrae is small with the true transverse process forming a small portion at the posterior aspect of foramen transversarium. The lateral aspect of the foramen transversarium, called the costal elements develop from the lateral mesenchymal condensations. The costal elements along with the pedicle form the boundaries of foramen transversarium. All except the true transverse process at the dorsomedial aspect of the foramen are costal vestiges. The cervical nerve roots exit above the corresponding vertebra. These nerve roots are close to the vertebral artery at the neural foramen and are commonly subjected to mechanical irritation at this region.

Anomalies are more common at the dens than at lamina, pedicle and posterior elements [4]. Craniovertebral junction anomalies when associated with joint instability cause neural irritation. Anomalies of dens such as os odentoideum are less likely to cause occipital headache and are more commonly associated with transient paresis and progressive myelopathy. Most common posterior element anomaly associated with neck pain is absence of 
pedicle and lamina defects [4]. These absent pedicle syndromes are more common in lower cervical vertebrae. Anomalies of lamina and posterior arch when associated with atlanto axial joint instability can cause momentary occipital neuralgia. Bony outgrowths such as osteophytes and bony ridges are known to narrow the foramen transversarium leading to vertebrobasilar insufficiency [5].

Foramen transversarium defects are less common and rarely cause symptoms [5]. The simultaneous foraminal abnormality at C1 and C2 in this case might be an isolated occurrence probably a vascular insult during development. Mechanical irritation and compression of the cervical nerve roots that exit above the corresponding vertebrae can occur at the lateral recess and neural foramina due to prolapsed disc, mass or tortuous vertebral artery [6].

Spinal canal stenosis at C2 causes cervical myelopathy due to cord compression. Cord compression is less likely associated with isolated occipital headache. The tortuous course of the vertebral artery can occur due to cervical junction anomalies, abnormal transverse foramina or just a normal variant. It can compress the spinal cord and the exiting upper nerve roots causing neurological pain $[2,3]$. The importance of investigating occipital headache lies in diagnosing this treatable aetiology, for mechanical decompression by microsurgery can provide complete relief and these anomalies can be easily overlooked.

\section{References}

1. Lozano AM, Vanderlinden G, Bachoo R, et al. Microsurgical C-2 ganglionectomy for chronic intractable occipital pain. Journal of Neurosurgery 1998; 89: 359-65.

2. Detwiler PW, Porter RW, Harrington TR, et al. Vascular decompression of a vertebral artery loop producing cervical radiculopathy. Journal of Neurosurgery 1998; 89: 485-8.

3. Shenglin W, Chao W, Yi L, et al. Anomalous vertebral artery in craniovertebral junction with occipitalisation of the atlas, Chinese Medical Journal 2009; 122: 2675-7.

4. Hosalkar HS, Sankar WN, Wills BP. Congenital osseous anomalies of the upper cervical spine. Journal of Bone and Joint Surgery 2008; 90: 337-48.

5. Sanchis-Gimeno JA, Martínez-Soriano F, Aparicio-Bellver L. Degenerative anatomic deformities in the foramen transversarium of cadaveric cervical vertebrae. Osteoporosis International 2005; 16: 1171-2.

6. Hunter CR, Mayfield FH Role of the upper cervical roots in the production of pain in the head. American Journal of Surgery 1949; 78: 743-51. 